\title{
Quality of Life Assessment of Growth Hormone Deficiency in Adults (QoL-AGHDA): Comparison of Normative Reference Data for the General Population of England and Wales with Results for Adult Hypopituitary Patients with Growth Hormone Deficiency
}

\author{
Maria Kołtowska-Häggström ${ }^{a, b}$ Susan Hennessy ${ }^{c}$ Anders F. Mattsson ${ }^{a}$ John P. Monson ${ }^{d}$ Paul Kind $^{c}$ \\ ${ }^{a}$ KIGS/KIMS/Acrostudy Medical Outcomes, Endocrine Care, Pfizer, Stockholm, and ${ }^{b}$ Department of Pharmacy, \\ Uppsala University, Uppsala, Sweden; ${ }^{\circ}$ Outcomes Research Group, Centre for Health Economics, University of \\ York, York, and d Department of Endocrinology, St Bartholomew's Hospital, Queen Mary University of London, \\ London, UK
}

\section{Key Words}

Quality of life/health-related quality of life .

Growth hormone deficiency in adults · Normative reference values

\begin{abstract}
Background/Aim: Age- and gender-specific reference values for the quality of life $(\mathrm{O} o \mathrm{~L})$ measures used in assessing the impact of growth hormone deficiency (GHD) are important. The objective of this study was to develop such data for the QoL-AGHDA instrument for the population of England and Wales and to demonstrate the QoL deficit in patients with GHD. Methods: For the purpose of this study, a questionnaire was developed that contained the EurQoL EQ-5D, QoL-AGHDA, questions recording an individual's general situation and social functioning, and a self-reported five-point rating scale of general health. The questionnaire was mailed out to a sample of 1,190 individuals drawn from the general population of England and Wales. Corresponding data for 836 patients were retrieved from KIMS (Pfizer International Metabolic Database). The postal survey data were
\end{abstract}

weighted to ensure that they were representative of the general population. Results: The mean weighted QoLAGHDA scores for the general population were 6.2 and 7.1 for men and women, respectively, compared with 13.6 and 15.7 for patients. For both males and females the differences in mean QoL-AGHDA scores between the general population and patients were statistically significant for all age categories $(p<0.01)$. In the general population the mean QoL-AGHDA score for each category of self-assessed health status increased progressively, indicating a poorer QoL as health status declined. Conclusions: This study reports QoL-AGHDA normative values for the population of England and Wales and confirms the extent of QoL impairment in patients with GHD in comparison with the general population.

Copyright $\odot 2005$ S. Karger AG, Basel

\section{Introduction}

The quality of life (QoL) affected by an individual's health status (health-related QoL; HR-QoL) is a widely recognized and measurable construct, despite the lack of

\section{KARGER}

Fax +4161306 1234 E-Mailkarger@karger.ch www.karger.com
(C) 2005 S. Karger AG, Basel 0301-0163/05/0641-0046\$22.00/0

Accessible online at:

www.karger.com/hre
Maria Kołtowska-Häggström, MD

KIGS/KIMS/Acrostudy Medical Outcomes

Pfizer Endocrine Care, SE-112 87 Stockholm (Sweden)

Tel. +468 69599 33, Fax +4686954026

E-Mail maria.koltowska-haggstrom@pfizer.com 
a clear definition [1], with relevance in a wide variety of diseases. It has become a standard endpoint in clinical studies [2] and is accepted as an indicator of a patient's overall health status, having parity with physical symptoms and signs of disease. It has particular importance for economic evaluation and healthcare decision-making [3]. The proper evaluation of HR-QoL requires appropriate age- and gender-specific reference values, which should ideally take account of cultural and ethnic differences. This requires access to country-specific normal values, which are needed not only for the measurement of HR-QoL in individuals but also for interpreting aggregated data from international multi-centre studies. In clinical trials, data obtained from internal control groups support analysis and interpretation. However, due to the usually small sample size and the strict inclusion and exclusion criteria inherent in all clinical trials, such data do not adequately reflect normal population values.

Growth hormone deficiency (GHD) in adults is a wellrecognized distinct clinical condition resulting from partial or complete pituitary failure. It is characterized by reduced life expectancy, increased prevalence of cardiovascular risk factors, adverse changes in body composition, reduced exercise tolerance, decreased bone mineral density with an increased fracture rate, and impaired QoL [4-6].

As early as 1962, Raben [7] reported improved vigour, well-being and ambition in a 35-year-old hypopituitary patient treated with growth hormone $(\mathrm{GH})$. Similar observations have been reported repeatedly [8]. The most consistent findings are related to energy levels, vitality, mental fatigue and emotional reactions [9-12] as well as to social isolation $[10,13]$ and anxiety [10]. Reduced selfconfidence has also been reported [9], as has a disturbed sex life [13], decreased physical mobility [9], dissatisfaction with body image [14] and poor memory [15]. These findings explain the widespread use of QoL measures in GH-deficient patients. Various instruments have been used to assess QoL in patients with GHD $[11,16]$. The Nottingham Health Profile, Psychological General WellBeing Schedule, Quality of Life Assessment of Growth Hormone Deficiency in Adults (QoL-AGHDA), Hospital Anxiety and Depression Scale, Life Fulfilment Scale, Mental Fatigue Questionnaire and Short Form 36 Health Survey are the most frequently used $[17,18]$. In addition to the QoL-AGHDA, which is the most commonly encountered condition-sensitive measure, another diseasespecific instrument (Questions on Life Satisfaction-Hypopituitarism; QLS-H) has been developed [19].

Country-Specific QoL-AGHDA Scores
Most published studies have analysed the effects of $\mathrm{GH}$ replacement therapy in comparison with baseline assessments or with control groups given placebo [20]. Some studies have compared GH-deficient patients with small samples of healthy individuals $[21,22]$ or patients with other chronic disorders [23, 24]. Few studies, however, have compared patients' QoL scores with general population values [25-29], which probably reflects the paucity of country-specific reference values.

It is an open question as to whether the appropriate comparative population should consist of normal individuals or patients with a different chronic disorder [30]. The latter possibly provides a control group more comparable to the patient group. However, as establishing the extent of pathology is critical, comparison with healthy individuals would seem to be preferable. Additionally, normal population reference data can be used in economic analyses; for example, in assessing the benefits of treatment and in healthcare decision making [31]. In the light of the recent National Institute for Clinical Excellence (NICE) guidelines on selection of adult patients with GHD for GH replacement [31], the availability of UKspecific reference values for the QoL-AGHDA would be of particular importance.

This study presents QoL-AGHDA normative data for England and Wales and demonstrates the differential health status of hypopituitary adults with GHD.

\section{Subjects and Methods}

Conduct of Survey and Applied Questionnaire

For the purpose of this study a questionnaire was designed that contained standard versions of EQ-5D (a generic measure of HRQoL) [32] and QoL-AGHDA [14], together with questions recording an individual's general situation and social functioning using items from the KIMS (Pfizer International Metabolic Database) Patient Life Situation Form (PLSF), a standard part of the KIMS protocol [33]. A standard five-point rating scale (excellent, very good, good, fair, poor) of self-reported health status was also incorporated.

EQ-5D is a two-part questionnaire designed as a generic measure of HR-QoL. The first part is based around a self-classification of health defined in terms of five dimensions: mobility, self-care, usual activities, pain/discomfort and anxiety/depression. Each dimension is divided into three levels of problem corresponding to none, some or extreme. The complete classification defines a total of 245 health states for each of which there is a corresponding score based on values obtained from a national survey of the general population [34].

Respondents record their assessment of the level of problem in each dimension, which is then converted into a single index score $\left(\mathrm{EQ}-5 \mathrm{D}_{\text {index }}\right)$. The second part records the respondent's rating of their health status on a visual analogue scale (EQ-5D $D_{\text {ASS }}$ ) from 0 
(worst imaginable health) to 100 (best imaginable health). EQ-5D has been widely used in clinical and population studies over the past 15 years [35].

QoL-AGHDA is based on a concept that QoL is the degree to which human needs are satisfied [36]. It was constructed based on in-depth interviews of adult patients with GHD attending the Christie Hospital in Manchester, and consists of 25 items that evokes yes/no answers, acknowledging or denying certain problems [14]. The instrument has been shown to be reliable and valid with a high level of internal consistency [29].

The questionnaire was sent out in the first half of 2003 to 1,190 members of a general population survey panel maintained by the Outcomes Research Group in York. The panel comprises members of the general public over 18 years of age in England and Wales who had previously agreed to take part in such research surveys and had given their consent to be contacted. Members of the panel had been recruited over a period of 3 years prior to this study and had previously taken part in at least one survey related to the assessment of health status. A total of some 2,000 individuals had given written informed consent to be re-contacted for the purposes of subsequent health surveys. A reminder letter was sent out to nonresponders after the initial mailing. Patient information was retrieved from KIMS and hence included QoL-AGHDA and PLSF data, but not EQ-5D results or self-reported health status.

\section{Statistical Analysis}

The distributions of age and gender in the postal survey differed from those recorded for the general population in the 2001 census for England and Wales; hence, results obtained from the postal survey were weighted to achieve a closer representation of the general population. The proportion of the census population for each gender and 10-year age group was computed and compared with the corresponding observed proportion in the survey. The ratio of the observed: expected proportion in each gender/age group was used as a weighting factor for individual respondents in the postal survey. Weighted responses were used to compute mean values for QoL-AGHDA scores, relevant demographics and EQ-5D values.

Other results presented here are based on analysis of the unweighted survey responses and are employed for the direct comparisons between the general population and KIMS patients for each age and gender categories. The QoL-AGHDA was treated as a cardinal variable. Problem rates within EQ-5D dimensions and self-rated EQ-5D $D_{\text {VAS }}$ were also analysed as cardinal data. Analysis of variance (ANOVA) and $t$-tests were used to examine subgroup differences. Data are given as means \pm SD unless otherwise indicated.

\section{Population Sample}

The achieved sample comprised 1,007 individuals - 435 men (43\%) and 572 women (57\%). There were 183 non-responders of whom 103 were men and 80 were women. The response rates were $81 \%$ for men and $87 \%$ for women.

Respondents aged $18-19$ due to a very low number $(n=6)$ were excluded from the analysis. One respondent aged 90 was grouped with those in the 80- to 89-year age group. A total of 1,001 respondents was included in the subsequent analysis, of whom $434(44 \%)$ were men and 567 (56\%) women. The mean age of the participants was 54.4 years (56.9 years for men and 42.5 years for women). Although invitations to join the survey panel were sent out to a random sample of people on the electoral register, the data in Table 1 suggest that respondents who took part in the survey do not reflect key socio-demographic features of the general population. Compared with the population of England and Wales recorded in the 2001 census, the survey sample has a higher proportion of women (57\% compared with 52\%) and is substantially older than the general population. The distribution of respondent age also differed from the general population. Those taking part in this survey were twice as likely to have stayed in education after the minimum school-leaving age (64\% compared with $32 \%$ ) and nearly twice as likely to have attained a degree or similar professional qualification (41\% and 24\%). Health status was similar to that reported in a national survey of the general population in 1998 [37], although a higher proportion of the sample had problems with pain or discomfort than those in the general population. This may reflect their older age range.

\section{Missing Data}

QoL-AGHDA scores were available for 921 respondents; a score was not computed where one or more items were missing. Data for the EQ-5D $D_{\text {VAS }}$ were present for 978 respondents and for both the EQ-5DVAS and QoL-AGHDA for 902 respondents.

\section{Adult Hypopituitary Patients with GHD}

Information regarding adult hypopituitary patients with GHD was retrieved from KIMS, which contains data on more than 9,000 adult patients with GHD worldwide. KIMS was launched in 1994 at the request of endocrinologists and healthcare decision makers to monitor the outcomes and safety of long-term GH replacement therapy in these patients, treated in a conventional clinical setting. Data are collected at clinic visits on specially designed case report forms. The data collection process is monitored by study monitors who verify the data with the original source documents, and the quality of the data entered has been audited and confirmed. It is a condition of entry to KIMS that each centre obtains approval from their local ethics committee and that patients give informed consent, either verbally or in writing, depending on the local legal requirements. The UK clinics are major contributors to the database, with approximately 2,000 patients. For the present study a subset of data was prepared from 836 patients (407 men and 429 women; $49 \%$ and $51 \%$, respectively) who originated from England and Wales. These patients had either never received GH replacement or had not received $\mathrm{GH}$ for at least 6 months before entry into KIMS.

Mean age at onset of pituitary disease was $33.5 \pm 15.8$ years (34.6 \pm 16.7 years for men and $32.4 \pm 15.0$ years for women), at diagnosis of GHD $40.9 \pm 15.5$ years $(41.4 \pm 16.3$ years for men and $40.2 \pm 14.8$ years for women). At entry to KIMS (baseline visit) the mean age was $45.3 \pm 13.2$ years $(45.8 \pm 3.5$ years for men and $44.9 \pm 12.9$ years for women). All patients had severe GHD, indicated by a GH peak below $3.0 \mu \mathrm{g} / 1$ on dynamic testing. The mean insulin-like growth factor I (IGF-I) SD score was $-1.8 \pm$ $1.9(-1.4 \pm 1.9$ in men and $-2.2 \pm 1.8$ in women $)$. In 154 patients (18.4\%) GHD was diagnosed in childhood (CO-GHD) and in 682 $(81.6 \%)$ in adulthood (AO-GHD). Isolated GHD was diagnosed in 95 patients (11.4\%); all others had at least one additional pituitary hormone deficit, with the majority $(36.7 \%)$ having panhypopituitarism. All patients received appropriate hormonal replacement in relation to other pituitary hormone deficits. The most common causes for developing GHD were non-functioning pituitary adenoma (24.3\%), prolactinoma (13.5\%), Cushing's disease (13.2\%) and 
Table 1. Characteristics of respondents compared with national data and KIMS patients

\begin{tabular}{|c|c|c|c|}
\hline & $\begin{array}{l}\text { Survey } \\
\text { participants } \\
(\mathrm{n}=1,001)\end{array}$ & $\begin{array}{l}\text { Comparative } \\
\text { national } \\
\text { data }\end{array}$ & $\begin{array}{l}\text { KIMS patients } \\
(\mathrm{n}=836)\end{array}$ \\
\hline \multicolumn{4}{|l|}{ Gender, \% } \\
\hline Male & 43 & 48 & 48 \\
\hline Female & 57 & $52 *$ & 52 \\
\hline \multicolumn{4}{|l|}{ Age, years } \\
\hline Mean & 54 & 48 & 45 \\
\hline Range & $18-90$ & $18-102$ & $20-84$ \\
\hline \multicolumn{4}{|c|}{$\%$ of respondents/population aged } \\
\hline $18-39$ & 17 & 40 & 34 \\
\hline $40-59$ & 46 & 34 & 51 \\
\hline $60+$ & 37 & $27 *$ & 15 \\
\hline \multicolumn{4}{|c|}{ Employment status/ main activity, \% } \\
\hline In paid employment & 48 & 54 & 54 (16 - sickness benefit) \\
\hline Retired & 33 & 21 & 14 (8 - early retirement) \\
\hline Housework/childcare & 10 & $13^{* *}$ & 7 \\
\hline \multicolumn{4}{|l|}{ Personal situation } \\
\hline$\%$ living alone & 17 & N/A & 19 \\
\hline$\%$ living with children & 34 & N/A & 59 \\
\hline $\begin{array}{l}\text { Assistance with daily activitie } \\
\text { (\% requiring assistance) }\end{array}$ & 12 & N/A & 29 \\
\hline Long-standing illness ( $\%$ yes) & 31 & $43^{* *}$ & 100 \\
\hline
\end{tabular}

Health status

Self-rating of health during the previous 12 months N/A

$\begin{array}{lrc}\text { Excellent } & 10 & 13 \\ \text { Very good } & 33 & 31 \\ \text { Good } & 37 & 34 \\ \text { Fair } & 16 & 17 \\ \text { Poor } & 4 & 4^{*}\end{array}$

EQ-5D dimensions

$\%$ reporting any problems on each dimension N/A

Mobility

$22 \quad 18$

Self-care $\quad 6 \quad 5$

Usual activities $\quad 23 \quad 19$

Pain/discomfort $\quad 47 \quad 37$

Anxiety/depression $29 \quad 23^{* *}$

EQ-5D visual analogue scale rating of health state

$\begin{array}{lll}\text { Range } & 10-100 & 68-92^{* *} \\ \text { Mean } & 79 & 82 \\ \text { SD } & 16 & 17\end{array}$

N/A

$\mathrm{SD}$

$16-17$

* Census 2001: website - www.statistics.gov.uk/STATBASE/Figures for England and Wales.

** Health Survey for England 1998. Figures for England only. N/A = Not available. craniopharyngioma (10.8\%). Only $9.7 \%$ of patients had undergone irradiation alone for their primary disease, $36 \%$ underwent surgery, and both treatments were administered to $30.4 \%$ of patients. QoLAGHDA scores were obtained at baseline, and none of the patients had received $\mathrm{GH}$ treatment for at least 6 months preceding entry to the KIMS database. Fractures were reported by $29.5 \%$ of patients and hypertension by $19 \%$. Other frequently recognized (>5\%) concomitant morbidities in this group of patients were coronary heart disease, history of neoplasm other than etiological to GHD, arthrosis and diabetes mellitus. 
Table 2. QoL-AGHDA scores in the general population and GH-deficient patients in KIMS

\begin{tabular}{|c|c|c|c|c|c|c|c|c|c|c|}
\hline \multirow[t]{2}{*}{ Sex } & \multirow[t]{2}{*}{ Age group } & \multicolumn{4}{|c|}{ General population } & \multicolumn{4}{|c|}{ KIMS patients } & \multirow[t]{2}{*}{$\mathrm{p}$} \\
\hline & & $\mathrm{n}$ & mean & SD & median & $\mathrm{n}$ & mean & SD & median & \\
\hline \multirow[t]{8}{*}{ Male } & $20-29$ & 12 & 5.8 & 4.3 & 4.0 & 61 & 12.6 & 7.2 & 12.0 & $<0.01$ \\
\hline & $30-39$ & 38 & 6.9 & 5.7 & 8.0 & 78 & 13.1 & 6.4 & 13.5 & $<0.001$ \\
\hline & $40-49$ & 78 & 5.8 & 6.0 & 5.0 & 94 & 13.9 & 6.9 & 15.0 & $<0.001$ \\
\hline & $50-59$ & 98 & 6.7 & 6.1 & 5.0 & 105 & 14.7 & 5.9 & 16.0 & $<0.001$ \\
\hline & $60-69$ & 106 & 5.6 & 5.0 & 4.0 & 56 & 13.1 & 6.5 & 13.0 & $<0.001$ \\
\hline & $70-79$ & 55 & 6.9 & 5.2 & 7.0 & 13 & 13.5 & 6.5 & 13.0 & $<0.001$ \\
\hline & $80+$ & 16 & 6.4 & 4.6 & 5.5 & & & & & \\
\hline & Total & 403 & 6.2 & 5.6 & 5.0 & 407 & 13.6 & 6.6 & 14.0 & $<0.001$ \\
\hline \multirow[t]{8}{*}{ Female } & $20-29$ & 25 & 6.6 & 5.7 & 5.0 & 59 & 14.5 & 5.8 & 15.0 & $<0.001$ \\
\hline & $30-39$ & 82 & 6.8 & 5.7 & 5.0 & 86 & 15.1 & 6.9 & 16.0 & $<0.001$ \\
\hline & $40-49$ & 124 & 7.4 & 6.7 & 5.0 & 129 & 16.7 & 5.8 & 18.0 & $<0.001$ \\
\hline & $50-59$ & 135 & 6.7 & 6.0 & 5.0 & 97 & 16.4 & 5.7 & 16.0 & $<0.001$ \\
\hline & $60-69$ & 94 & 6.5 & 5.5 & 5.0 & 47 & 14.4 & 7.7 & 17.0 & $<0.001$ \\
\hline & 70-79 & 45 & 7.7 & 6.8 & 7.0 & 10 & 13.8 & 4.1 & 13.5 & $<0.001$ \\
\hline & $80+$ & 13 & 6.9 & 4.4 & 7.0 & 1 & 11.0 & & 11.0 & \\
\hline & Total & 518 & 7.1 & 6.1 & 5.0 & 429 & 15.7 & 6.3 & 16.0 & $<0.001$ \\
\hline Total & & 921 & 6.7 & 5.8 & 5.0 & 836 & 14.7 & 6.5 & 15.0 & $<0.001$ \\
\hline
\end{tabular}

\section{Results}

\section{General Population Scores}

The weighted QoL-AGHDA score was $6.2 \pm 0.3$ (mean $\pm \mathrm{SEM})$ in men and $7.1 \pm 0.3$ (mean $\pm \mathrm{SEM})$ in women. The overall score was $6.7 \pm 0.2($ mean \pm SEM). The age- and gender-specific QoL-AGHDA scores in the population sample and for KIMS patients are presented in table 2. Although mean QoL-AGHDA scores for any age group tended to be higher for women compared with men, ANOVA indicated that the variability in QoLAGHDA scores was not significantly explained by either age or gender.

\section{Comparisons between the General Population and \\ Patients, Including Patient Sub-Groups}

For both men and women the differences in mean QoL-AGHDA scores between the general population and patients were statistically significant $(\mathrm{p}<0.001$ in most age categories), indicating the differential impact of GHD in adults with respect to QoL measured by the QoLAGHDA.

Patients with CO-GHD were significantly younger than those with AO-GHD (31 vs. 48 years respectively; $\mathrm{p}<0.001)$. Patients with CO-GHD also recorded better QoL as measured by QoL-AGHDA than those with AO-
GHD (mean scores, respectively, 12.6 SD 6.6 and 15.1 SD 6.3, $\mathrm{p}<0.001)$. When age and gender were simultaneously controlled for, the difference in QoL remained in younger patients but was lost in older patients ( $p$ for interaction between age at baseline and onset 0.03 ).

\section{Health Status of the General Population Sample, \\ Including Relevant QoL-AGHDA Scores}

A history of long-standing illness was reported by $31 \%$ of the general population sample. Although the most commonly recognized problems were related to the cardiovascular system, such as angina pectoris and hypertension, and musculo-skeletal disorders, the poorest HR-QoL was observed in those individuals who reported psychological problems (mean score, $13.5 \pm 5.9$ ). Almost one-quarter of KIMS patients reported hypertension and heart problems and 8\% arthrosis. Interestingly, 39\% of KIMS patients reported one concomitant disease in their medical history and almost 23\% more than one. Mean QoLAGHDA scores in these groups were $14.6 \pm 6.3$ and 16.0 \pm 6.3 , respectively, compared with $13.9 \pm 6.6$ in patients with no co-morbidities. The former can be compared with individuals from the general population with only one chronic disease $(n=266)$ and in whom the mean QoL-AGHDA score was 6.2 \pm 5.6 . 


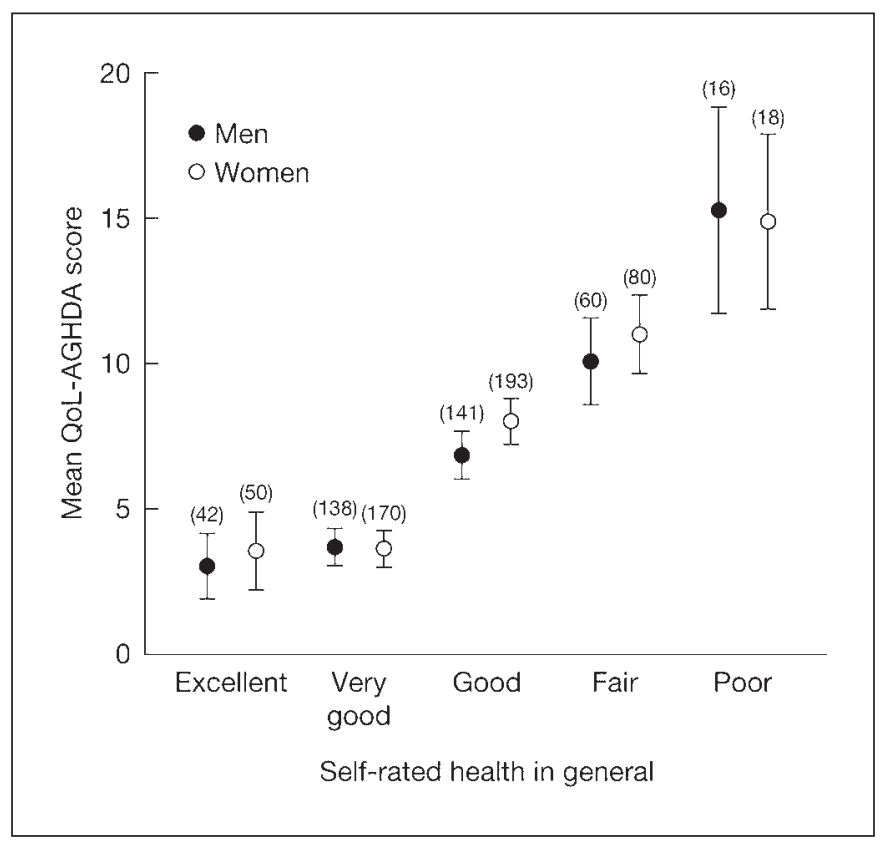

Fig. 1. Mean QoL-AGHDA scores and 95\% confidence intervals according to self-reported health during the last 12 months in the general population. Numbers of respondents are shown in parentheses.

As expected, mean QoL-AGHDA scores increased in the general population as the number of reported health problems increased $(4.9 \pm 5.1$ for individuals who reported no problems, $6.2 \pm 5.6$ for those reporting one problem and $8.9 \pm 8.0$ for those reporting two or more health problems). These differences are statistically significant (ANOVA: $F=42.0$, d.f. $=2, \mathrm{p}<0.001$ ). The same tendency was observed in KIMS patients, where QoLAGHDA scores increased with the number of co-morbidities (ANOVA: $F=6.6$, d.f. $=2, p=0.002$ ). The ability of the standard five-point rating scale to discriminate between population subgroups of different health status has been well documented [38]. Figure 1 shows that the mean QoL-AGHDA scores and 95\% confidence intervals for each of these categories increased progressively, indicating a reduced QoL as self-assessed health status worsened (ANOVA: $F=88.7$, d.f. $=4, p=0.001$ ). Similarly, a strong negative correlation was observed between EQ$5 \mathrm{D}_{\mathrm{VAS}}$ and QoL-AGHDA scores $(\mathrm{r}=-0.53, \mathrm{p}<0.001)$ (fig. 2); that is, fewer problems were recognized by the QoL-AGHDA in individuals reporting a better general health status on the EQ-5D $\mathrm{DAs}_{\mathrm{V}}$.

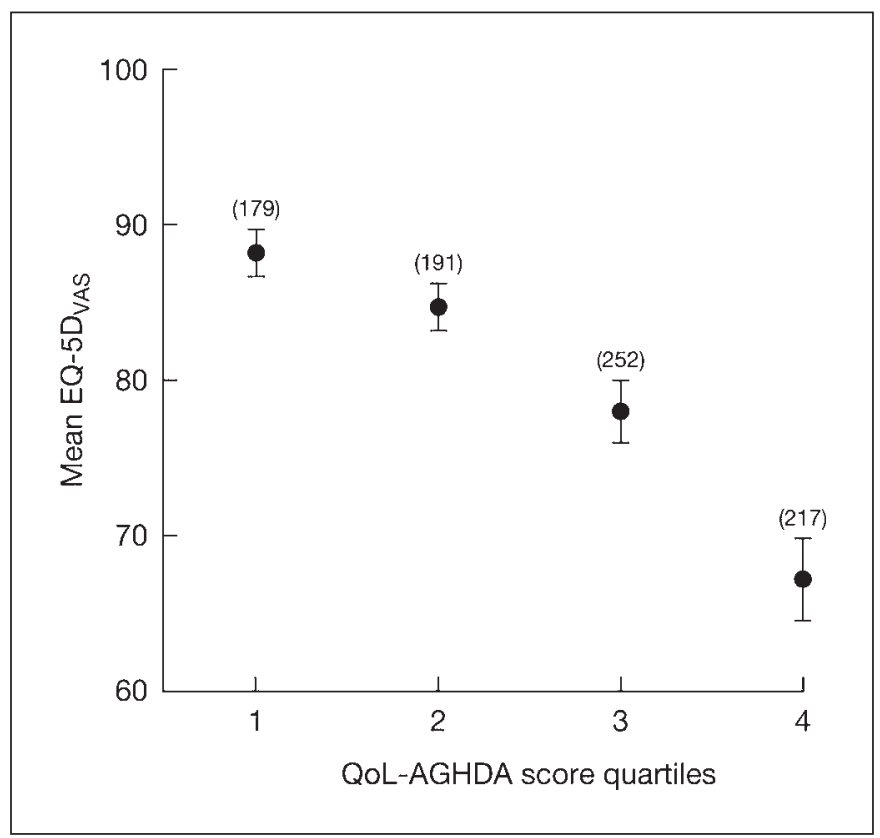

Fig. 2. Mean EQ-5D $D_{\text {VAS }}$ scores and $95 \%$ confidence intervals according to QoL-AGHDA score quartiles in the general population. Quartiles are defined as: 1 (0-25\%), AGHDA scores 0 and 1; 2 (26-50\%), AGHDA scores 2-4; 3 (51-75\%), AGHDA scores 5-10; $4(76-100 \%)$, AGHDA scores $11-25$. Numbers of respondents are shown in parentheses.

\section{The General Population with Scores above the Mean for Patients}

Of the general population survey respondents, 103 (9.7\%) had a QoL-AGHDA score greater than the patient mean of 13.6 for men and 15.7 for women. Of these, 47 (46\%) were men and 56 (54\%) were women. Analysis of respondents in this subgroup of the general population revealed that they were twice as likely to report having a long-standing illness or disability than were patients who scored below the patient mean QoL-AGHDA score (56\% vs. $28 \%$ ) and more often needed help with their daily activities (57\% vs. 30\%). Reported levels of problems on any of the five EQ-5D dimensions were two to three times higher in this subgroup $(\mathrm{p}<0.001)$. Their self-rated health status was worse, with $53 \%$ describing their health status as fair or poor, and their EQ-5D $\mathrm{DAS}_{\mathrm{VA}}$ rating was significantly lower $(61.2 \pm 21.1)$. Comparisons between subgroups who scored below and above the mean for patients are shown in table 3. Additionally, individuals from the general population with scores above the patient mean were more likely to have numerous health problems for which they were currently receiving treatment, with mus- 
Table 3. EQ-5D scores in population subgroups who scored below and above the QoL-AGHDA mean for patients with GHD

Respondents scoring Respondents scoring below the mean for above the mean for patients, $\% \quad$ patients, $\%$

Health status

Self-rating of health during the previous 12 months

Very Good

Good

Fair

11

36

36
37

14

2

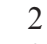

2
8

8
37

34

19

EQ-5D dimensions

$\%$ Reporting any problems on each dimension

$\begin{array}{lll}\text { Mobility } & 19 & 46\end{array}$

$\begin{array}{lll}\text { Self-care } & 4 & 18\end{array}$

Usual activities $\quad 20 \quad 55$

Pain/discomfort $43 \quad 77$

Anxiety/depression $22 \quad 81$

EQ-5D visual analogue scale rating of health state

$\begin{array}{lll}\text { Range } & 10-100 & 10-100 \\ \text { Mean } & 80.8 & 61.2 \\ \text { SD } & 14.8 & 21.1\end{array}$

culo-skeletal (39\% vs. $22 \%$ ) and psychological problems $(26 \%$ vs. $6 \%)$ being most common. Respondents in the age groups 40-49 and 50-59 years were slightly more likely to have QoL-AGHDA scores above the patient mean.

\section{Discussion}

This study reports for the first time QoL-AGHDA reference values for England and Wales, based on a large sample of the general population, and compares them with corresponding results from a large cohort of untreated patients with GHD from the same countries. The sample achieved by the postal survey differed somewhat in terms of its gender and age compared with the characteristics of the general population, tending to be older and more likely to be female. Despite this limited divergence, the overall health status of the sample was remarkably similar to that reported in the general population in terms of the five-point classification of health status. The use of weighted survey data will have largely adjusted for any age and gender differences, but the effect of any other uncontrolled variables remains largely unknown. This might marginally reduce the strength of any assertion that the study is based on a representative sample of the general population, but in the circumstances this is regarded as unlikely.

QoL-AGHDA is available in a number of different language versions but country-specific normal reference values derived from relevant general populations have been published only for Sweden [29] and Spain [28]. Two further studies in the USA [39] and UK [22] have compared healthy controls with GH-deficient patients, but did not yield normative reference values due to the relatively small sample sizes involved. The results from Sweden and Spain indicate remarkable country-specific discrepancies, with the UK values being considerably higher - thus indicating a poorer QoL - than those for the other two countries. The existence of cross-country variation has been previously elsewhere [40, 41].

Our results are consistent with those from previously published studies [9-15], that indicate a substantial QoL deficit in untreated hypopituitary patients with GHD. The statistically significant differences between patients and individuals in the reference population persisted across all age and gender categories. However, it is worth noting that the nature of the KIMS database might generate a potential selection bias that could account for some of this striking variation. In the UK, the major criterion for patient eligibility for $\mathrm{GH}$ replacement is impaired QoL and, as KIMS is a database of patients receiving such treatment, levels of QoL may be worse than in the GHdeficient population at large. Nonetheless, it should be noted that the sample represents approximately $20 \%$ of the total population of adult patients in the UK with GHD.

In contrast to the UK normative values for QLS-H [25], differences between gender and age categories in the population sample in the present study were not statistically significant. With regard to gender differences in QoL-AGHDA scores this finding runs counter to previous studies that have reported higher scores for female patients with GHD [42]. The possible explanation for a poorer QoL in female patients, in contrasts to the situation in controls, requires further studies, but could be related to their lower IGF-I levels [43] that is compensated for in healthy women.

The data reported here reveal the negative impact of co-morbidities on QoL-AGHDA scores. However, in most instances such co-morbidities account for a lower proportion of the deficit in QoL than in patients with GHD. The practical implication of this finding is that concurrent disorders should always be considered when 
interpreting QoL-AGHDA scores in patients with GHD. The study by Barkan [39], showing high QoL-AGHDA scores in patients with active acromegaly, supports our inference that it would be more appropriate to describe the QoL-AGHDA as a condition-sensitive rather than a condition-specific measure. Its sensitivity derives from the fact that it was developed by in-depth exploration of symptoms in patients with GHD $[14,15]$. The discriminatory validity of the QoL-AGHDA for use in GH-deficient adults should therefore be seen in terms of this sensitivity. The evidence from this study also indicates that the QoL-AGHDA is capable of discriminating between groups in the general population with known differences in health status. In that respect it demonstrates a performance comparable to that of a generic measure.

The strong inverse correlation between QoL-AGHDA scores and the standard five-point rating scale for self-reported health status [38] (higher scores in individuals reporting poorer health status) provides further evidence of the discriminatory power of the QoL-AGHDA.

As almost $10 \%$ of the general population survey respondents scored higher than the patient mean, we examined this subgroup in detail. It transpired that their poor QoL was probably due to the presence of a wide range of concurrent health problems, which were additionally confirmed by their self-reported health-status and a low
EQ-5D $D_{\text {VAS }}$ rating. The greater need for help in daily activities and their lower rate of employment appear to be logical consequences of their worse health status.

In conclusion, this study reports normative reference values for the QoL-AGHDA in the population of England and Wales. Variations in such values between countries suggest that the interpretation of QoL measures should take account of country-specific normative values. This is particularly important when data from different countries are pooled, and relevant statistical methods should be applied to account for cross-country differences.

Finally, our study reconfirms the extent of QoL impairment in patients with GHD in comparison with the general population. However, as these findings are based on the population of England and Wales, similar studies are desirable to establish whether the results can be generalized to other countries and populations.

\section{Acknowledgements}

We would like to express our thanks to the participants of KIMS in the UK who provided the data on their patients and to the colleagues working at KIGS/KIMS/Acrostudy Medical Outcomes in Stockholm. Without their commitment, support and daily hard work the KIMS database would not exist.

\section{References}

1 Sanders C, Egger M, Donovan J, Tallon D, Frankel S: Reporting on quality of life in randomized controlled trials: bibliographic study. Br Med J 1998;317:1191-1194.

2 Fayers PM, Machin D: Preface; in: Quality of life: Assessment, Analysis and Interpretation. Chichester, Wiley, 2000, pp 1-36.

3 Berger ML, Bingefors K, Hedblom EC, Pashos CL, Torrance GW, Dix Smith M: Health-related quality of life; in Berger ML, Bingefors K, Hedblom EC, Pashos CL, Torrance GW (eds): Health Care, Cost, Quality and Outcomes. Lawrenceville, ISPOR, International Society for Pharmacoeconomics and Outcomes Research, 2003, pp 129-131.

4 Carroll PV, Christ ER and the members of Growth Hormone Research Society Scientific Committee: Bengtsson B- $\AA$, Carlsson L, Christiansen JS, Clemmons D, Hintz R, Ho K, Laron Z, Sizonenko P, Sönksen PH, Tanaka T, Thorner M: Growth hormone deficiency in adulthood and the effects of growth hormone replacement: a review. J Clin Endocrinol Metab 1998;83:382-395.

\section{Abs R, Bengtsson BÅ, Hernberg-Ståhl E, Mon- son JP, Tauber JP, Wilton P, Wüster C: GH replacement in 1034 growth hormone deficient hypopituitary adults: demographic and clinical characteristics, dosing and safety. Clin Endo- crinol 1999;50:703-713.}

6 Wüster C, Abs R, Bengtsson B- $\AA$, Bennmarker H, Feldt-Rasmussen U, Hernberg-Ståhl E, Monson J, Westberg B, Wilton P: The influence of growth hormone deficiency, growth hormone replacement therapy, and other aspects of hypopituitarism on fracture rate and bone mineral density. J Bone Miner Res 2001; 16:398-405.

7 Raben AS: Clinical use of human growth hormone. N Engl J Med 1962;266:82-86.

8 Burman P, Deijen JB: Quality of life and cognitive function in patients with pituitary insufficiency. Psychother Psychosom 1998;67:154167.

-9 Björk S, Jonsson B, Westphal O, Levin JE: Quality of life of adults with growth hormone deficiency: a controlled study. Acta Paediatr Scand Suppl 1989;356:55-59.
10 McGauley GA, Cuneo R, Salomon F, Sönksen PH: Psychological well-being before and after growth hormone treatment in adults with growth hormone deficiency. Horm Res 1990; 33(suppl 4):52-54.

11 Wallymahmed ME, Foy P, Shaw D, Hutcheon R, Edwards EHT, MacFarlane IA: Quality of life, body composition and muscle strength in adult growth hormone deficiency: the influence of growth hormone replacement therapy up to 3 years. Clin Endocrinol 1997;47:439-446.

12 Wirén L, Bengtsson B-Å, Johannsson G: Beneficial effects of long-term $\mathrm{GH}$ replacement therapy on quality of life in adults with GH deficiency. Clin Endocrinol 1998;48:613620.

13 Rosén T, Wirén L, Wilhelmsen L, Wiklund I, Bengtson B-A: Decreased psychological wellbeing in adult patients with growth hormone deficiency. Clin Endocrinol 1994;40:111116.

14 McKenna SP, Doward LC, Alonso J, Kohlmann T, Niero M, Prieto L, Wirén L: The QoLAGHDA: an instrument for the assessment of quality of life in adults with growth hormone deficiency. Qual Life Res 1999;8:373-383. 
15 Hunt SM, McKenna SP, Doward LC: Preliminary report on the development of a diseasespecific instrument for assessing quality of life of adults with growth hormone deficiency. Acta Endocrinol 1993;128(suppl 2):37-40.

16 Chrisoulidou A, Kousta E, Beshyah SA, Robinson S, Johnston DG: How much, and by what mechanisms, does growth hormone replacement improve the quality of life in GHdeficient adults? Baillières Clin Endocrinol Metab 1998;12:261-279.

17 Koltowska-Häggström M, Kind P: Evaluating outcomes in adult growth hormone deficiency (AGHD): the status of quality of life (QoL) measurement in clinical studies. ENDO Abstract Book, P2-320, p 383. Chevy Chase, The Endocrine Society Press, 2003.

- 18 Radcliffe DJ, Pliskin JS, Silvers JB, Cuttler L: Growth hormone therapy and quality of life in adults and children. Pharmacoeconomics 2004:22:499-524.

- 19 Herschbach P, Henrich G, Strasburger CJ, Feldmeier H, Marin F, Attanasio AM, Blum WF: Development and psychometric properties of a disease-specific quality of life questionnaire for adult patients with growth hormone deficiency. Eur J Endocrinol 2001;145:255265

20 Deijen JB, van der Veen EA: The influence of growth hormone $(\mathrm{GH})$ deficiency and $\mathrm{GH}$ replacement on quality of life in GH-deficient patients. J Endocrinol Invest 1999;22:127136.

21 Li Voon Chong JSW, Groves T, Foy P, Wallymahmed ME, MacFarlane IA: Elderly people with hypothalamic-pituitary disease and untreated GH deficiency: clinical outcome, body composition, lipid profiles and quality of life after 2 years compared to controls. Clin Endocrinol 2002;56:175-181.

22 Malik IA, Foy P, Wallymahmed M, Wilding JPH, MacFarlane IA: Assessment of quality of life in adults receiving long-term growth hormone replacement compared to control subjects. Clin Endocrinol 2003;59:75-81.

-23 Page RCL, Hammersley MS, Burke CW, Wass JAH: An account of the quality of life of patients after treatment for non-functioning pituitary tumors. Clin Endocrinol 1997;46:401406.

-24 Wallymahmed ME, Foy P, MacFarlane IA: The quality of life of adults with growth hormone deficiency: comparison with diabetic patients and control subjects. Clin Endocrinol 1999;51:333-338.
25 Blum WF, Shavrikova EP, Edwards DJ, Rosilio M, Hartman ML, Marin F, Valle D, van der Lely AJ, Attanasio AF, Strasburger CJ, Henrich $\mathrm{G}$, Herschbach P: Decreased quality of life in adult patients with growth hormone deficiency compared with general populations using the new, validated, self-weighted questionnaire, Questions on Life Satisfaction Hypopituitarism Module. J Clin Endocrinol Metab 2003;88:4158-4167.

26 Rosilio M, Blum WF, Edwards DJ, Shavrikova EP, Valle D, Lamberts SWJ, Erfurth EM, Webb SM, Ross RJ, Chihara K, Henrich G, Herschbach P, Attanasio AF: Long-term improvement of quality of life during growth hormone $(\mathrm{GH})$ replacement therapy in adults with GH deficiency, as measured by questions on Life Satisfaction-Hypopituitarism (QLS-H). J Clin Endocrinol Metab 2004;89:1684-1693.

27 Rosilio M, Berthezene F, Blum WF, Shavrikova EP, Herschbach P, Henrich G: The qualityof-life questionnaire QLS-H(c): validation of the French language version of the questionnaire in patients with growth hormone deficiency and collection of reference data in the general population. Ann Endocrinol 2004;65: 439-450.

-28 Badia X, Lucas A, Sanmarti A, Roset M, Ulied A: One-year follow-up of quality of life in adults with untreated growth hormone deficiency. Clin Endocrinol 1998;49:765-771.

29 Wirén L, Whalley D, McKenna SP, Wilhelmsen L: Application of a disease-specific, quality-of-life measure (QoL-AGHDA) in growth hormone-deficient adults and a random population sample in Sweden: validation of the measure by Rasch analysis Clin Endocrinol 2000;52:143-152.

30 Murray RD, Shalet SM: The use of self-rating questionnaires as a quantitative measure of quality of life in adult growth hormone deficiency. J Endocrinol Invest 1999;22:118126.

31 National Institute for Clinical Excellence (Nice), Technology Appraisal 64: Human Growth Hormone (Somatotropin) in Adults with Growth Hormone Deficiency. Nice, 2003.

32 EuroQoL Group: EuroQoL - a new facility for the measurement of health-related quality of life. Health Policy 1990;16:199-208.

33 Hernberg-Ståhl E, Luger A, Abs R, Bengtsson B-Å, Feldt-Rasmussen U, Wilton P, Westberg B, Monson JP: Healthcare consumption decreases in parallel with improvements in quality of life during GH replacement in hypopituitary adults with GH deficiency. J Clin Endocrinol Metab 2001;86:5277-5281.
-34 Dolan P: Modeling valuations for EuroQol health states. Med Care 1997;35: 1095-1108.

- 35 Greiner W, Weijen T, Nieuwenhuizen M, Oppe S, Badia X, Busschbach J, Buxton M, Dolan P, Kind P, Krabbe P, Ohinmaa A, Parkin D, Roset M, Sintonen H, Tsuchiya A, de Charro F: A single European currency for EQ5D health states; results from a six-country study. Eurn J Health Econ 2003;4:222-231.

36 Hunt SM, McKenna SP: The QLDS: a scale for the measurement of quality of life in depression. Health Policy 1992;22:307-319.

- 37 Kind P, Dolan P, Gudex C, Williams AH: Variations in population health status: results from a UK national survey. Br Med J 1998; 316:736-741.

38 Franks P, Gold MR, Fiscella K: Sociodemographics, self-rated health, and mortality in the US. Soc Sci Med 2003;56:2505-2514.

39 Barkan AL: The 'Quality of life-assessment of growth hormone deficiency in adults' questionnaire: can it be used to assess quality of life in hypopituitarism? J Clin Endocrinol Metab 2001;86:1905-1907.

- 40 Hürny C, Bernhard J, Gelber RD, Coates A, Castiglione M, Isley M, Dreher D, Peterson H, Goldhirsch A, Senn HJ for the International Breast Cancer Study Group: Quality of life measures for patients receiving adjuvant therapy for breast cancer: an international trial. Eur J Cancer 1992;28:118-124.

41 Inglehart R, Jacques-Rene R: Aspirations adapt to situations - but why are the Belgians so much happier than the French? A cross-cultural analysis of the subjective quality of life; in Andrews FM (ed): Research on the Quality of Life. Ann Arbor, Institute for Social Research, University of Michigan, 1986, pp 156.

42 Bengtsson B-Å, Abs R, Bennmarker H, Monson JP, Feldt-Rasmussen U, Hernberg-Ståhl E, Westberg B, Wilton P, Wüster C: The effects of treatment and the individual responsiveness to $\mathrm{GH}$ replacement therapy in $665 \mathrm{GH}-$ deficient adults. J Clin Endocrinol Metab 1999;54: 3929-3936.

43 Mukherjee A, Monson JP, Jonsson PJ, Trainer PJ, Shalet SM: Seeking the optimal target range for insulin-like growth factor I during the treatment of adult growth hormone disorders. J Clin Endocrinol Metab 2003;88:5865-5870. 